\title{
MODELING MICROTOPOGRAPHY IN BASIN IRRIGATION
}

\section{By E. Playán, ${ }^{1}$ J. M. $\quad$ Faci, ${ }^{1}$ and A. Serreta ${ }^{2}$}

SUMMARY: This paper presents the extension of a two-dimensional basin irrigation model to allow simulation of water flow over a porous bed with nonuniform slope. The model is validated with field data and used to explore the relationship between microtopography and basin irrigation performance.

KEY WORDS: Basin, Irrigation, Topography, Performance, Efficiency, Uniformity.

ABSTRACT: Microtopography has long been regarded as a key variable affecting basin irrigation performance. This paper reports on the extension of a flat bed two-dimensional basin irrigation model to the simulation of irrigation events in basins with microtopography. The model incorporates the local surface slopes in the $x$ and $y$ directions to the governing set of partial differential equations. Three field experiments were used to validate the extended model. Elevation was measured over irregular grids, and geostatistical techniques were applied to estimate the nodal elevation of the computational grids. Results indicate that inclusion of microtopography improves the estimation of the advance and recession processes and produces lower, more realistic estimates of irrigation performance. To further explore this phenomenon, two numerical

${ }^{1}$ Res., Unidad de Suelos y Riegos, Servicio de Investigación Agraria (DGA). Laboratorio Asociado de Agronomía y Medio Ambiente CSIC-DGA. Apdo. 727, 50080 Zaragoza, Spain.

2 Asst. Prof., Departamento de Ingeniería del Diseño y Fabricación, Universidad de Zaragoza, EUPH, Crta. Zaragoza S/N, 22071 Huesca, Spain. 
experiments were devised consisting of a series of simulations on a level basin with gradually growing microtopography. The times of advance and recession and the irrigation performance indexes are largely affected by field microtopography, even if laser leveling is used. 


\section{INTRODUCTION}

One-dimensional modeling has long been applied to many surface irrigation problems. In basin irrigation, the wide range of combinations of field shapes and inflow configurations results in water flow patterns that often require a distortion of the geometry to permit use of one-dimensional models. Playán et al. (1994a; 1994b) presented a basin irrigation model based on the two-dimensional shallow water equations. This model reportedly improved the estimation of the characteristic times of the irrigation event and the configuration of the advancing front. The model was also used to explore the influence of spatially varied infiltration on irrigation performance.

Although the definition of basin irrigation implies a flat soil surface (Hart et al., 1980) the undulations of the soil surface can have an important effect on the advance and recession phases of an irrigation event (Walker and Skogerboe, 1987). These undulations will be referred to as microtopography, denoting the existence of topographical patterns embedded into the general zero-slope leveling of the field. Playán et al. (1995) used data from an irrigation evaluation to characterize the relevance of microtopography in basin irrigation performance. Their experimental data revealed that microtopography could account for $73 \%$ and $34 \%$ of the variability in opportunity time and soil water recharge, respectively.

One-dimensional models are based on the hypothesis that all variables are constant across the width of the field. As a result, basin irrigation models have usually been designed under the assumption that the field is perfectly leveled (Clemmens and Strelkoff, 1979; Fonken et al., 1980; Schmitz and Seus, 1989). Two-dimensional models enable effective exploration of the effects of spatial variation of two key variables in basin irrigation: infiltration and elevation.

Generalized use of laser leveling techniques in basin irrigation has revealed a relationship between microtopography and time of advance, uniformity 
and efficiency. Microtopography is often characterized by means of the standard deviation (SD) of the elevation of the field.

Several authors (Bucks and Hunsaker, 1987; Leão de Sousa et al., 1993) have reported a standard deviation of about $1 \mathrm{~cm}$ as characteristic of laser leveled basins.

In this work, a two-dimensional hydrodynamic model of basin irrigation with microtopography is presented. Three field experiments were used to validate the model, focusing on the advance and recession phases of the irrigation event. Finally, two numerical experiments were performed to explore the variation of the time of advance, time of recession, uniformity and efficiency with increasing microtopography for a given basin. 


\section{MATERIALS AND METHODS}

\section{Two-dimensional basin irrigation simulation with microtopography}

Vertically integrated two-dimensional shallow water flow over a porous bed is governed by a set of three partial differential equations accounting for conservation of mass and conservation of momentum in the two cartesian spatial dimensions. According to Akanbi and Katopodes (1988), the governing equations can be written as:

¡Error!

¡Error!

¡Error!

where $x(m)$ and $y(m)$ are the spatial coordinates; $t$ is the time $(s) ; p$ is the unit discharge in the $x$ direction $\left(\mathrm{m}^{2} / \mathrm{s}\right)$; $q$ is the unit discharge in the $y$ direction $\left(\mathrm{m}^{2} / \mathrm{s}\right)$; $h$ is the flow depth $(m)$; $i$ is the infiltration rate $(\mathrm{m} / \mathrm{s}) ; g$ is the acceleration of gravity $\left(\mathrm{m} / \mathrm{s}^{2}\right) ; n$ is the Manning roughness coefficient; and $z_{0}$ is the surface bed elevation $(\mathrm{m})$.

The well-known Kostiakov-Lewis formula can be used to approximate the infiltration rate: 
$i=k a \tau^{a-1}+f_{0}$

where $\tau 5$ is the opportunity time ( $\min ) ; a$ is an empirical exponent; $k$ is an empirical coefficient $\left(\mathrm{m} / \mathrm{min}^{\mathrm{a}}\right)$; and $\mathrm{f}_{0}$ is an empirical coefficient $(\mathrm{m} / \mathrm{min})$. The infiltrated depth ( $\mathrm{z}$ ) can be computed as the time integral of $i$.

Complete simulation of an irrigation event in the presence of microtopography was accomplished in this work by the consecutive use of two approaches: hydrodynamic and mass balance.

Hydrodynamic approach. The model presented by Playán et al. (1994a) was based on the solution of Eqs. 1-3 using an explicit leapfrog finite differencing scheme. In the original model, bed elevation was assumed constant throughout the field and therefore its derivatives respect to the $x$ and $y$ coordinates were set to zero. In the present work, bed elevation of the computational nodes is an input to the model, and its spatial partial derivatives are computed using second-order finite difference approximations. Similar approaches have been successfully used in river and tidal estuary modeling (Walters and Cheng, 1979; Su et al., 1980; Benqué et al., 1982; Ambrosi et al., 1994).

Mass balance approach. Immediately after the time of cut off (TC), flow velocity rapidly decreases in all nodes. When the unit discharge in the $x$ and $y$ directions becomes smaller than $10^{-4} \mathrm{~m}^{2} / \mathrm{s}$ at all nodes, the hydrodynamic procedure is abandoned and the remaining overland volume is infiltrated according to the Kostiakov equation, the nodal opportunity time and the local elevation. At this time, the water level $(L)$ is assumed to become instantaneously uniform and remain uniform until the time of recession (TR). $L$ is equal to $z+h$ if $\mathrm{h}$ is greater than zero. The time step $(\Delta \mathrm{t})$ is set to $5 \mathrm{~min}$ and remains constant until the end of the simulation. 
The following procedure is followed to determine the new water depths. First, the volume of overland depth $\left(V_{h}\right)$ is computed by numerical integration of $h$ over the domain $(\Omega)$. The second step is to determine the water level using the equation:

$$
V_{h}=\iint_{\Omega}(L-z) d x d y
$$

Only positive values of L-Z (flooded nodes) are considered in the integral. Finally, nodal values of $h$ are computed subtracting local elevation from the water level. Negative values of $\mathrm{h}$ are set to zero. During each time step, all flooded nodes infiltrate the depth of water corresponding to their local opportunity time, in an amount equal to i $\Delta t$. At the end of each step the infiltrated depth is subtracted from the local overland depth. If, at a particular node, $\mathrm{h}$ becomes negative, its flow depth is set to zero, indicating recession at the considered node.

A mass balance is performed at the end of each time step. The volumes of overland and infiltrated water are updated by numerical integration of $h$ and $z$ over the domain. The process is repeated until complete recession.

\section{Characterization of microtopography in irrigated fields}

In the field experiments reported in this work a radiometric total station was used to measure the surface bed elevation of a series of observation points forming an irregular network inside the irrigated fields. Semivariogram analysis (Clark, 1979) was used to estimate the spatial dependency of elevation. The experimental semivariogram (a plot of semivariance vs. distance) is characterized by three parameters termed nugget, sill, and range. The nugget is the value of the semivariance at zero distance. In theory the nugget should equal zero, implying that all measurements at a given location must yield the same result, but it commonly takes nonzero values, indicating the existence of nonsystematic 
errors or variability at a smaller scale than measured. The distance independent, stable value of the experimental semivariogram referenced from the nugget is the sill, and the range is the distance at which the semivariance equals the sill plus the nugget. The sum of sill and nugget is a good estimate of the semivariance of the data set, while the range is an indication of the average distance in which bed elevation is correlated, and is therefore an estimate of the average extent of local hills and depressions. Kriging (Journel et al., 1978) was applied to estimate the value of surface elevation at unmeasured locations.

\section{Irrigation evaluation}

The procedures used in this research for field irrigation evaluation were adapted from the classic work by Merriam and Keller (1978). During the advance and recession phases, the location of the front was recorded in situ with the help of colored flags. A flag was stuck at every alignment break of the advancing or recession front, at an average distance of 5-10 m. After drying of the field surface, the exact location of the flags was surveyed with the same total station used for the characterization of surface bed elevation. Advance was measured at $10-20$ min intervals and recession at 1 hour intervals. Field determination of the location of the recession front resulted complex because of

the furrowing effect produced by tillage equipment and because of very small scale topographical effects.

Infiltration was measured with single infiltrometer rings provided with automatic water level recorders using the adjusted infiltration approach. Two rings were used in each experiment. Provisions were made to avoid lateral flow from the bottom of the rings. In field experiments 1 and 3 infiltration measurements were performed during the irrigation evaluation, starting at the time when the advance front reached the ring. In field experiment 2 a circular earthen ditch with a radius of $1 \mathrm{~m}$ was built around the ring and kept flooded 
during the experiment. Irrigation performance was assessed using three indexes proposed by Merriam and Keller (1978): distribution uniformity (DU), application efficiency (Ea), and potential efficiency of the low quarter (PELQ). DU is computed as a percentage of the average irrigation depth at the $25 \%$ less watered area respect to the average irrigation depth. Ea is the percentage of the applied water that is stored in the root zone. Finally, PELQ is the application efficiency computed using the average irrigation depth at the $25 \%$ less watered area as the desired irrigation depth. 


\section{MODEL VALIDATION}

Three field experiments were performed for model validation purposes, focusing on the advance and recession processes separately. Experiment 1 was used to validate the hydrodynamic modeling of the advance process. For this purpose, a data set involving an evaluation of the advance phase of a border irrigation event was used. The leveling of the border was poor and therefore the configuration of the advance front was severely distorted by microtopography. Different grid sizes were used to assess their influence on the estimation of the location of the advancing front and on the magnitude of the mass balance error. Field experiment 2 was performed to allow for proper testing of the mass balance approach used to simulate the recession phase. A small square basin, $256 \mathrm{~m}^{2}$ in size, was irrigated, and the location of the recession front was measured in detail. Finally, experiment 3 consists on an irrigation evaluation of a real scale basin and the simulation of all phases of the irrigation event. Advance data were used for model validation, but detail recession measurement proved to be unmanageable. This is due to the complexity of the configuration of the recession front, whose governing pattern, created by microtopography, is much finer than the size of the basin.

\section{Field experiment 1}

A blocked-end border $288 \mathrm{~m}$ long and $28.8 \mathrm{~m}$ wide was irrigated from a point outlet located approximately in the middle of one of its short sides with a constant discharge of $0.158 \mathrm{~m}^{3} / \mathrm{s}$ for $80 \mathrm{~min}$. Microtopography was characterized with a soil survey of 423 points. Regression analysis revealed a longitudinal slope of $0.079 \%$. The standard deviation of the residuals of the regression line (SD) was $4.03 \mathrm{~cm}$. A geostatistical analysis of surface elevation revealed existence of a spatial structure characterized by a nugget of $3 \mathrm{~cm}^{2}$, a sill 
of $15.5 \mathrm{~cm}^{2}$, and a range of $27 \mathrm{~m}$. The experimental and theoretical semivariograms of surface elevation are presented in Fig. 1. The infiltration parameters were estimated as: $\mathrm{k}=0.0531 \mathrm{~m} / \mathrm{min}^{\mathrm{a}} ; \mathrm{a}=0.245$; and $\mathrm{f}_{0}=0.000026$. The field had just been ripped, and Manning $n$ was estimated to be 0.06 .

The border was discretized using four different grids, whose characteristics are presented in Table 1. The grids were named after its approximate node spacing in meters, as G6, G5, G4 and G3. In all cases, the inflow was considered distributed uniformly along the short side of the border. This approximation should have little effect on the configuration of the advancing front and on the characteristic times and indexes of the irrigation event, since the border is 10 times longer than wide (Playán et al., 1994b).

The residuals of the regression of surface elevation vs. distance in the $x$ direction were scaled down linearly to create five reliefs with SD's ranging from $0.0 \mathrm{~cm}$ (perfect leveling with a $0.079 \%$ slope) to $4.0 \mathrm{~cm}$ (the original relief of the border). The reliefs were computed using kriging, and were named after their SD, as D0, D1, D2, D3, and D4. The advance phase of the irrigation event was simulated for cases resulting from combinations of the four grids and the five reliefs.

Fig. 2 presents the location of the advancing front at times ranging from 10 to $80 \mathrm{~min}$. A high spot located about $60 \mathrm{~m}$ from the inlet strongly distorts the advancing front and results in an island after time $40 \mathrm{~min}$. The area comprised between $y=0 \mathrm{~m}$ and $\mathrm{y}=10 \mathrm{~m}$ is locally depressed throughout the border. This results in a faster advance in the area, observed since time 20 min. Simulation for case G3D0 results in a straight, vertical advancing front, characteristic of a quasi-one-dimensional simulation. Cases G6D4 and G3D4 present the effect of grid fineness on the estimation of the characteristics of the advancing front. The fine grid produces better estimates of the configuration of the front at the early stages of the event, while G6D4 provides a better fit for times over 40 min. Case 
G3D4 simulates the island until time $80 \mathrm{~min}$, whereas case G6D4 completely floods the area prior to time $60 \mathrm{~min}$. Besides grid fineness, flooding of this high spot is related to the estimation of the roughness parameter $n$. A smoother porous bed would result in smaller flow depths and therefore a larger island.

Advance diagrams for selected combinations of grids and SD's are presented in Fig. 3. Case G3D4 shows good agreement with experimental data, although other grids yield better estimates of flooded area at particular times. Advance for case G3D0 (perfect leveling) is faster than experimental data until time $40 \mathrm{~min}$, and slower from then on.

Fig. 4 presents the time evolution of the mass balance error corresponding to the four grids with SD $4 \mathrm{~cm}$ and the five reliefs with a grid size of approximately $3 \mathrm{~m}$. The effect of grid fineness is not clear, though there seems to be a trend of error reduction with finer grids in the presence of microtopography. On the other hand, SD has a strong influence on mass balance error. G3D0 shows an error of $0.0 \%$ throughout the simulation, indicating correctness of the numerical procedures. Increasing values of SD result in larger absolute values of the final error, except for case G3D3, whose performance is better than could be expected. The unflooded high spot (reached by the front at about time $20 \mathrm{~min}$ ) drastically increases the absolute value of the mass balance error in all simulated cases.

\section{Field experiment 2}

A large field was laser leveled to zero slope, ripped and rolled to smoothen the soil surface. A small square plot of $16 \times 16 \mathrm{~m}$ was marked inside this field and an earth ditch was built along its contour to create the small basin where field experiment 2 was performed.

A regular 289-node network was used to discretize the basin, with a node spacing of $1 \mathrm{~m}$ in the $\mathrm{x}$ and $\mathrm{y}$ directions. To avoid interference between 
infiltration measurement and the advance and recession processes, the ring infiltrometers were located just outside the basin. The coefficients of the Kostiakov-Lewis equation were estimated as: $\mathrm{k}=0.0222 \mathrm{~m} / \mathrm{min}^{\mathrm{a}} ; \mathrm{a}=0.230$; and $\mathrm{f}_{0}$ $=0.000000 \mathrm{~m} / \mathrm{min}$. The field was irrigated with a constant discharge of 0.00212 $\mathrm{m}^{3} / \mathrm{s}$ for $155.5 \mathrm{~min}$. A value of 0.04 was assumed for the Manning $\mathrm{n}$.

An irregular network of 108 nodes (separated approximately $1.5 \mathrm{~m}$ ) was surveyed to characterize surface bed elevation. The standard deviation of elevation was $0.92 \mathrm{~cm}$. The semivariogram presented in Fig. 1 is characterized by a nugget of $0.0 \mathrm{~cm}^{2}$; a sill of $1.62 \mathrm{~cm}^{2}$; and a range of $6.0 \mathrm{~m}$.

During the irrigation evaluation procedure the location of the advancing front was recorded at 15 min intervals. These data were used to estimate the opportunity time at the time of cut off at all the computational nodes. Application of the infiltration equation yielded the estimated values of the nodal infiltrated depths, which were integrated over the domain to compute the infiltrated volume at TC. This volume was subtracted from the gross irrigation volume $\left(V_{g}\right)$ to obtain an estimate of the overland volume. The nodal values of opportunity time and the overland volume were supplied to the recession module of the microtopography model to obtain estimates of the location of the recession front at specified time intervals.

Fig. 5 is a plot of the location of the recession front as observed and simulated with the microtopography model at times 1, 2, 3, and 4 hours after TC. The flooded area is presented shaded. A vertical line shade was used for the observed recession, whereas a horizontal line shade was used for the simulated recession. Areas shaded with a square grid indicate coincidence between observed and estimated flooded areas. Table 2 presents observed and estimated percents of flooded area at the same time intervals.

Simulated recession shows satisfactory coincidence with measured data, indicating that microtopography is a key variable in the recession process, even in 
laser leveled basins. While basin irrigation models developed to date consider simultaneous recession in the whole basin, a recession phase lasting more than four hours was measured in this experiment.

Table 2 reveals an overestimation of the flooded area towards the end of the simulation, particularly for $\mathrm{t}=4 \mathrm{~h}$ after TC. This bias might be due to an error in the measured recession induced by evaporation from the ponded surface, which is not considered by the model. This could be relevant to the estimation of flooded areas if the water profile was shallow enough, as presumably happens at the end of recession.

Conceptually, the microtopography model could have been applied to the whole irrigation event of this field experiment 2, but a limitation was found in the reliability of the proposed hydrodynamic scheme when the flow depth is small in relation to the relief of the field. These results are in agreement with those obtained in field experiment 1 (large mass balance errors resulting from large SD's). In this particular case, the low inflow discharge produced a very shallow overland flow which in combination with a relief with an SD of $0.92 \mathrm{~cm}$, produced large, unacceptable mass balance errors.

\section{Field experiment 3}

The basin presented in Fig. 6, with an area of $8591 \mathrm{~m}^{2}$, was irrigated from its upper left corner. The domain was discretized using 279 nodes spaced $6 \mathrm{~m}$ in the $x$ and $y$ directions, yielding a simulated area of $8568 \mathrm{~m}^{2}$. The soil had just been tilled and infiltration was characterized by the following set of parameters of a Kostiakov-Lewis equation: $\mathrm{k}=0.00823 \mathrm{~m} / \mathrm{min}^{\mathrm{a}} ; \mathrm{a}=0.402 ;$ and $\mathrm{f}_{0}=0.000000$ $\mathrm{m} / \mathrm{min}$.

Discharge was $0.130 \mathrm{~m}^{3} / \mathrm{s}$ from time $0 \mathrm{~min}$ to time $10 \mathrm{~min}$, and $0.180 \mathrm{~m}^{3} / \mathrm{s}$ from time $10 \mathrm{~min}$ to time $110 \mathrm{~min}$, which was the time of advance and the time of cut off. Manning n was taken as 0.10 . 
The field had been graded to zero slope with traditional means years ago. To characterize elevation, 305 points of the basin were surveyed. The standard deviation of surface elevation was found to be $2.51 \mathrm{~cm}$. As shown in Fig. 1, the theoretical semivariogram for field experiment 3 presented a nugget of $1.2 \mathrm{~cm}^{2}$, a sill of $4.8 \mathrm{~cm}^{2}$, and a range of $12 \mathrm{~m}$. The rough soil surface created by tillering, and the ample sampling spacing (about $5 \mathrm{~m}$ ) resulted in a nonzero value of the nugget. No statistically significant general slope could be found in the basin.

Fig. 6 also presents the location of the advancing front as observed during the irrigation evaluation and as simulated using the flat bed model and the microtopography model. The advance profiles were not largely distorted by microtopography, indicating that the leveling of the basin was not uncommonly poor. Measured advance is, in general, slower than both simulated advances, although the microtopography model yields better estimates of the total flooded area than the flat bed model. Inclusion of microtopography in the model also results in better approximations of the configuration of the advancing front. The advance process is therefore sensitive to surface microtopography, which results in a distorted advancing front and a slower advance.

Table 3 confronts the results of both simulations. The error in the estimation of the time of advance (TA) is $10.4 \%$ for the flat bed model and $6.2 \%$ for the microtopography model. The flat bed model predicts simultaneous recession in all computational nodes, and therefore, the time of depletion (TD) equals the time of recession (TR). Results from the microtopography model reveal a large difference between both times, reflecting the existence of a recession phase 1550 min long, spanning from recession at the highest spot to recession at the lowest spot. Microtopography severely affects the performance indexes, with reductions of 8.6 points for DU and 9.9 points for PELQ. Decrease of the performance indexes is primarily due to the nonuniformity induced by the recession phase, which is much larger than the corresponding to the advance 
phase. This is evidenced by the duration of the recession phase, much longer than the advance phase (103.2 minutes). 


\section{MODEL APPLICATIONS: BASIN IRRIGATION}

The following two numerical experiments were performed to explore the nature of the dependance of the characteristic times and irrigation performance indexes on microtopography. Both numerical experiments are based on field experiment 3, whose relief was modified to generate a series of basins that represents a gradation in microtopography.

The original set of elevation data (305 nodes) was uniformly scaled up and down to yield 11 elevation sets of pre-established SD's ranging from $0.0 \mathrm{~cm}$ (flat bed) to $5.0 \mathrm{~cm}$, with a step of $0.5 \mathrm{~cm}$. Semivariogram analysis and kriging were used for each relief to obtain estimates of elevation at the computational nodes. In all model runs used for the numerical experiments, the mass balance error ranged between 1 and 3\%.

\section{Numerical experiment 1}

In this first numerical experiment, field experiment 3 was reproduced for the 11 different reliefs. Table 4 summarizes the results of the simulation, which focus on the characteristic times of the irrigation event. Fig. 7 is a plot of the advance curve for three selected values of $\operatorname{SD}(0.0,2.5$ and $5.0 \mathrm{~cm})$. Microtopography consistently steepens the advance curve and produces a delay in completion of advance. Fig. 8 presents the combined advance-recession diagrams for the same four values of SD. The differences in the advance process are of minor importance when compared to the differences in the recession process induced by microtopography. A value of $S D$ of $0.0 \mathrm{~cm}$ (flat bed simulation) results in a flat recession curve denoting TD $=$ TR. Growing microtopography produces early recession at the high spots and, particularly, delayed recession at the low spots. An interesting feature of Fig. 8 is that the time of recession at $50 \%$ of the area $\left(\mathrm{TR}_{50}\right)$ is independent of the 
microtopography status. This is confirmed by Table 4 , that shows only minor fluctuations in this parameter.

Fig. 9 is a plot of $T A, T D, T R_{50}$ and $T R$ vs. SD. Variation of all characteristic times approximately follows a linear pattern. The fluctuation of the variables in the considered range is $8.4 \%$ for the time of advance and $207 \%$ for the time of recession.

\section{Numerical Experiment 2}

In this numerical experiment the time of cut off for each relief was determined by trial and error to yield irrigation events with a common net irrigation depth $\left(Z_{n}\right)$ of $0.120 \mathrm{~m}$, with a corresponding net irrigation volume of $1031 \mathrm{~m}^{3}$. In agreement with the adequacy criterium proposed by Merriam and Keller (1978), the average irrigation depth at the low quarter of the basin was set equal to the net irrigation depth. This numerical experiment was designed to examine the relationship between microtopography, performance indexes and gross irrigation depth $\left(Z_{g}\right)$.

Table 5 presents the results of the experiment. The time of cut off ranged from $99.0 \mathrm{~min}$ for $\mathrm{SD}=0.0 \mathrm{~cm}$ to $116.2 \mathrm{~min}$ for $\mathrm{SD}=5.00 \mathrm{~cm}$. The times of advance (not shown in Table 5) coincide with the results of numerical experiment 1 , since all TC were larger than the corresponding TA in the previous experiment. Fig. 10 presents the variation of DU and Ea as a function of SD (in the range 0.0 $5.0 \mathrm{~cm}$ ). The figure reflects drops in DU and $\mathrm{Ea}$ of 14.2 and 15.9 points, respectively. Both responses are approximately linear in the considered range of SD. Fig. 11 is a plot of $Z_{g}$ and $Z_{n}$ vs. SD, denoting that for a fixed $Z_{n}$ of 0.120 $\mathrm{m}$, the gross irrigation depth must grow with SD to match the irrigation adequacy goal. A larger gross irrigation volume $\left(V_{g}\right)$ must be applied to fulfill the irrigation requirement in the presence of microtopography. This is denoted in Table 5 by 
the $17.9 \%$ total increase in $V_{g}$, and the corresponding increase in the volume of deep percolation $\left(V_{d p}\right)$ from $14 \mathrm{~m}^{3}(S D=0.0 \mathrm{~cm})$ to $211 \mathrm{~m}^{3}(\mathrm{SD}=5.0 \mathrm{~cm})$. 


\section{DISCUSSION}

The performance of the proposed microtopography model was compared with field data to validate the hydrodynamic and mass balance routines used to simulate the advance and recession processes, respectively. The hydrodynamic module improved the agreement between measured and estimated advance with respect to the flat bed model in two experiments involving a border and a basin. Microtopography-based estimates were in closer agreement with field data in both the configuration of the advancing front and the trajectory of the advance curve. In the studied range, grid fineness improved the estimation of the configuration of the advancing front and had some positive effect on the mass balance error.

The mass balance module used to simulate the recession phase produced estimations of the location of the recession front that showed good agreement with measurements from field experiment 2 . This is a significant improvement from flat bed models, whose recession phase induces no variability in infiltrated water depth. Evaporation from the water surface can partially explain the overestimation of the flooded surface at the latter stages of recession.

The characteristics of the semivariograms corresponding to the field experiments (Fig. 1) suggest that laser leveling scales down the semivariance and the range, but does not eliminate microtopography. If the range was similar to the radius of the root zone of agricultural crops it could be argued that the resulting variability of the irrigation depth would be irrelevant for agronomic purposes. Ranges of 27, 6 and $12 \mathrm{~m}$ result in areas of over- and under-irrigation whose extent exceeds by far the area explored by the roots of a single plant. This was confirmed by Playán et al. (1995), who found a range of $10 \mathrm{~m}$ for the soil moisture recharge induced by flood irrigation of a laser-leveled basin. The nonzero value of the nugget in field experiments 1 and 3 suggest that more 
intense sampling should be performed to fully characterize the relief of the fields. A finer sampling grid would also result in a better fit between observed and measured configurations of the advancing front.

A limitation was found in the applicability of the hydrodynamic procedure. A certain balance is required between flow depth and surface topography to avoid large spatial gradients of flow depth, particularly in the vicinity of the advancing front. Such conditions might violate the assumptions that led to the derivation of vertically integrated expressions of the shallow water equations (Bassett, 1972), resulting in large mass balance errors.

Results of the numerical experiments confirm that microtopography can play an important role in attaining the potential high efficiency associated with level-basin irrigation (Dedrick et al., 1982). The times of advance and, particularly, recession are largely affected by microtopography. Consequently, DU and PELQ are reduced in the presence of soil surface undulations.

According to the results of the numerical experiments, the residual microtopography after laser-controlled leveling (with an assumed SD of $1 \mathrm{~cm}$ ) increased the time of advance and recession by $1.4 \%$, and $34.9 \%$, respectively, when compared to the results of simulation using a flat bed model (numerical experiment 1). Numerical experiment 2 shows that this residual relief can result in a decrease in DU and Ea of 2.9 and 3.5 points, respectively, and increase irrigation water application by a 3.6\% respect to ideal leveling conditions. These effects on the irrigation performance indexes result form a single experiment, and therefore can not be considered general. They should be regarded as an indication of the existence of a threshold in attainable basin irrigation efficiency dictated by microtopography. Since the actual accuracy in land leveling is probably close to its technical limit, basin irrigation models should be adapted to estimate irrigation performance in the best attainable leveling conditions (laser leveling), or in the actual microtopographical conditions of the considered basin. 
Laser controlled leveling can improve the quality of irrigation return flows by decreasing deep percolation losses from irrigated basins. This in turn results in a diminished mass of solutes (salts, fertilizers and/or chemicals) leached from the soil profile (Rhoades and Suarez, 1977). This beneficial effect can be illustrated by the results of numerical experiment 2, where reduction of SD from $5 \mathrm{~cm}$ to 1 $\mathrm{cm}$ decreased deep percolation losses by an amount of $185 \mathrm{~m}^{3}$ per ha and irrigation event.

Extensive use of the proposed model would be unpractical, because characterization of microtopography requires specialized topographic equipment, intense data collection and analysis, and time consuming simulation. The model could be more efficiently used to establish empirical relations between SD and the characteristic times and performance indexes of the irrigation event. This task should be eased by the linearity shown by all tested times and indexes when plotted against SD. The input to such relations would consist of the flat bed model prediction of a characteristic time or performance index, an estimate of SD, and a reduced number of other related parameters such as discharge, area, or infiltration. The time of recession at $50 \%$ of the area $\left(\mathrm{TR}_{50}\right)$ could be an interesting parameter to be included in these simplified relations since it is related to infiltration, basin area and inflow discharge, and it does not seem to be microtopography-dependant. The output would be a microtopography-adjusted estimate of the considered time or index. Determination of SD for this purpose would only require soil surface elevation measurements at a short number of random locations within the basin.

Use of flat bed models to solve the inverse problem in basin irrigation might be misleading in poorly graded fields, where the advance process can be severely delayed by microtopography. The resulting parameters could reflect unrealistic, high infiltration and/or roughness parameters due to the inherent limitations of flat bed models. 
The reported model could be extended to cover all phases of border irrigation, with the additional difficulty that, in this type of irrigation, recession occurs while overland water is flowing downstream. In these conditions the hydrodynamic module should be used to simulate all phases of the irrigation event. This would require more simulation time and adjustments in the code. Microtopography should be less important in border irrigation, since the presence of a general slope diminishes the volume of water stored in local depressions.

Microtopography is not the only source of spatial variability affecting surface irrigation. Among the soil physics variables related to irrigation, infiltration has been identified as an important source of variability. Bautista and Wallender (1985), and Jaynes and Hunsaker (1989) characterized the effect of spatially varied infiltration in irrigation performance. Successful attempts have been made to implement this feature in furrow (Wallender, 1986), border (Jaynes and Clemmens, 1986), and basin irrigation (Playán et al., 1994b). A model combining microtopography and spatially varied infiltration could explain a large percentage of the variability found in soil moisture recharge due to irrigation. 


\section{CONCLUSIONS}

The proposed model for basin irrigation with microtopography could be used as a tool to assess irrigation performance in poorly graded basins. Results of numerical experiments indicate that state of the art leveled basins show lower performance indexes than perfectly leveled fields, suggesting the need for adjustments in the results of flat bed basin irrigation models, even if laser-controlled leveling is used.

Results indicate that the standard deviation of surface elevation is an important factor in basin irrigation management. In practical applications involving large farms or irrigation districts, measurements of this variable could be coupled with field experiments and computer simulations to assess the convenience of laser leveling. From an economic standpoint, farmers and planners could use these procedures to balance the benefits of increased irrigation uniformity and decreased water use and solute leaching with the cost of the leveling operation.

This model should also be regarded as part of an ongoing process to incorporate the sources of spatial variability in irrigation depth into the current hydrodynamic models of surface irrigation. The final outcome of this process should consist of better, more realistic estimates of irrigation performance indexes and characteristic times used in the design and evaluation of surface irrigation systems. The price to pay is a larger volume of input data. A balance between both aspects will be necessary to keep the models operative. 


\section{APPENDIX I: REFERENCES}

Akanbi, A. A. and Katopodes, N. D. (1988). "Model for flood propagation on initially dry land." ASCE J. Hyd. Div., 114(HY7), 689-706.

Ambrosi, D., Corti, S., Pennati, V. and Salieri, F. (1994). "A 2D numerical simulation of the Po river delta flow." In: Modelling of flood propagation over initially dry areas, P. Molinaro and L. Natale, Eds. ASCE, Milan, Italy. pp. 18-29.

Bassett, D. L. (1972). "A model for water advance in border irrigation." Transactions of the ASAE, 15(5), 992-995.

Bautista, E. and Wallender, W. W. (1985). "Spatial variability of infiltration in furrows." Transactions of the ASAE, 28(6), 1846-1855.

Benqué, J. P., Cunge, J. A., Feuillet, J., Hauguel, A. and Holly, F. M. (1982). "New method for tidal current computation." ASCE J. Waterways and Harbor Div., 108(3), 396-417.

Bucks, D. A. and Hunsaker, D. J. (1987). "Water use variability in irrigated level basins." Transactions of the ASAE, 30(4), 1090-1098.

Clark, I. (1979) Practical Geostatistics. Applied Science Publishers, Ltd., Ripple Road, Barking, Essex, England. 129 pp.

Clemmens, A. J. and Strelkoff, T. (1979). "Dimensionless advance for level-basin irrigation." ASCE J. Irrig. Drain. Div., 105(IR3), 259-273.

Dedrick, A. R., Erie, L. J. and Clemmens, A. J. (1982) "Level-Basin Irrigation." In: Advances in irrigation. D. Hillel, Ed. Academic Press, Inc., New York, NY. 105-145 pp.

Fonken, D. W., Carmody, T., Laursen, E. M. and Fangmeier, D. (1980). "Mathematical model of border irrigation." ASCE J. Irrig. Drain. Div., 106(IR3), 203-219.

Hart, W. E., Collins, H. G., Woodward, G. and Humperys, A. S. (1980) "Design and operation of surface systems." In: Design and operation of farm 
irrigation systems. M. E. Jensen, Ed. ASAE Monograph, St. Joseph, Michigan 501-582 pp.

Jaynes, D. B. and Clemmens, A. J. (1986). "Accounting for spatially varied infiltration in border irrigation models." Water resources research, 22(8), 1257-1262.

Jaynes, D. B. and Hunsaker, D. J. (1989). "Spatial and temporal variability of water content and infiltration on a flood irrigated field." Trans. ASAE., 32(4), 1229-1238.

Journel, A. G., Huijbregts and J., C. (1978) Mining geostatistics. Academic Press Inc. Ltd., London, England. 600 pp.

Leão de Sousa, P., Countinho, J. M. and Baguinho de Sousa, J. M. (1993) "O nivelamento de precisão e a sua manutenção. Condições essenciais para a automatização da rega de superfície," In: Desenvolvimento de equipamentos mecanizados para rega de gravidade. P. Leão de Sousa and M. R. Cameira, Eds. ISA/DER, Universidade Técnica de Lisboa, Lisboa, Portugal. 149 pp.

Merriam, J. L. and Keller, J. (1978) Farm irrigation system evaluation: a guide for management. Utah State University, Logan, Utah. 271 pp.

Playán, E., Walker, W. R. and Merkley, G. P. (1994a). "Two-dimensional simulation of basin irrigation. I: Theory." ASCE J. Irrig. Drain. Div., In press.

Playán, E., Walker, W. R. and Merkley, G. P. (1994b). "Two-dimensional simulation of basin irrigation. II: Applications." ASCE J. Irrig. Drain. Div., In press,

Playán, E., Faci, J. M. and Serreta, A. (1995). "Characterizing microtopographical effects on level-basin irrigation performance." Agricultural water management, Submitted for publication. 
Rhoades, J. D. and Suarez, D. L. (1977). "Reducing water quality degradation through minimized leaching management." Agricultural water management, 1, 127-142.

Schmitz, G. H. and Seus, G. S. (1989). "Analytical model of level basin irrigation." ASCE J. Irrig. Drain. Div., 115(IR1), 78-95.

Su, T. Y., Wang, S. T. and Alonso, C. V. (1980) "Depth-Averaging models of river flows," In: Fin. Elem. in Water Res. III, University of Mississippi. Vol. 5.223-5.235.

Walker, W. R. and Skogerboe., G. V. (1987) Surface irrigation. Theory and practice. Prentice-Hall, Inc., Englewood Cliffs, New Jersey. 386 pp.

Wallender, W. W. (1986). "Furrow model with spatially varying infiltration." Trans. ASAE., 29(4), 1012-1016.

Walters, R. A. and Cheng, R. T. (1979). "A two-dimensional hydrodynamic model of a tidal estuary." Advances in Water Resources, 2, 177-184. 


\section{APPENDIX II: NOTATION}

The following symbols are used in this paper:

a = Exponent of the Kostiakov-Lewis equation;

DU = Distribution uniformity (\%);

$\mathrm{Ea}=$ Application efficiency (\%);

$\mathrm{f}_{0}=$ Coefficient of the Kostiakov-Lewis equation $(\mathrm{m} / \mathrm{min})$;

$\mathrm{g}=$ Acceleration of gravity $\left(\mathrm{m} / \mathrm{s}^{2}\right)$;

$\mathrm{h} \quad=$ Flow depth $(\mathrm{m})$;

i $\quad=$ Infiltration rate $(\mathrm{m} / \mathrm{s})$;

k = Coefficient of the Kostiakov-Lewis equation $\left(\mathrm{m} / \mathrm{min}^{\mathrm{a}}\right)$;

$\mathrm{L}=$ Water level $(\mathrm{m})$;

$\mathrm{n}=$ Manning roughness coefficient;

$\mathrm{p} \quad=$ Unit discharge in the $\mathrm{x}$ direction $\left(\mathrm{m}^{2} / \mathrm{s}\right)$;

$P E L Q=$ Potential efficiency of the low quarter (\%);

$\mathrm{q}=$ = Unit discharge in the y direction $\left(\mathrm{m}^{2} / \mathrm{s}\right)$;

$\mathrm{SD}=$ = Standard deviation of soil surface elevation $(\mathrm{cm})$;

$\mathrm{t} \quad=$ Time (s);

$\mathrm{TA}=$ Time of advance $(\mathrm{min})$;

TC = Time of cut off (min);

TD = Time of depletion $(\mathrm{min})$;

$\mathrm{TR}=$ Time of recession $(\mathrm{min})$;

$\mathrm{TR}_{50}=$ Time of recession at $50 \%$ of the area $(\mathrm{min}) ;$

$\mathrm{V}_{\mathrm{dp}} \quad=$ Volume of water lost to deep percolation $\left(\mathrm{m}^{3}\right)$;

$V_{\mathrm{g}} \quad=$ Gross volume of water applied with irrigation $\left(\mathrm{m}^{3}\right)$;

$\mathrm{V}_{\mathrm{h}}=$ Overland volume $\left(\mathrm{m}^{3}\right)$;

$\mathrm{x} \quad=$ Spatial coordinate $(\mathrm{m})$; 


$$
\begin{aligned}
& \mathrm{y}=\text { Spatial coordinate }(\mathrm{m}) \text {; } \\
& \mathrm{z}_{0} \quad=\text { Surface elevation }(\mathrm{m}) \text {; } \\
& Z_{g} \quad=\text { Gross irrigation application depth (m); } \\
& Z_{n} \quad=\text { Net irrigation application depth }(m) \text {; } \\
& \text { 七6 = Opportunity time (min); and } \\
& \Omega=\text { Computational domain. }
\end{aligned}
$$




\section{APPENDIX III: TABLES}

Table 1. Characteristics of the grids used in field experiment 1: node spacing in the $x$ and $y$ coordinates ( $d x$ and $d y$ ), number of nodes in the $x$ and $y$ directions ( $\mathrm{nx}$ and ny), and total number of nodes ( $\mathrm{n}$ ).

\begin{tabular}{cccccc}
\hline Grid & $\begin{array}{c}\mathrm{dx} \\
(\mathrm{m})\end{array}$ & $\begin{array}{c}\mathrm{dy} \\
(\mathrm{m})\end{array}$ & $\mathrm{nx}$ & $\mathrm{ny}$ & $\mathrm{n}$ \\
$(1)$ & $(2)$ & $(3)$ & $(4)$ & $(5)$ & $(6)$ \\
\hline G6 & 6.000 & 5.760 & 49 & 6 & 294 \\
G5 & 4.966 & 4.800 & 59 & 7 & 413 \\
G4 & 4.000 & 4.114 & 73 & 8 & 511 \\
G3 & 3.000 & 3.200 & 97 & 10 & 970 \\
\hline
\end{tabular}


Table 2.Results of field experiment 2: percent flooded area at one hour intervals after the time of cut off as observed and simulated with the microtopography model.

\begin{tabular}{ccc}
\hline \multirow{2}{*}{$\begin{array}{c}\text { Time after cut off } \\
\text { (hours) } \\
(1)\end{array}$} & \multicolumn{2}{c}{ Flooded Area (\%) } \\
\cline { 2 - 3 } & Observed & $\begin{array}{c}\text { Microtopography } \\
\text { Model } \\
\end{array}$ \\
\hline 1 & $(2)$ & $(3)$ \\
\hline 2 & 89.8 & 79.1 \\
3 & 67.3 & 60.7 \\
4 & 34.2 & 45.3 \\
\hline
\end{tabular}


Table 3.Results of field experiment 3. Predictions of the flat bed model and the microtopography model for the following variables: time of advance (TA), time of depletion (TD), time of recession (TR), distribution uniformity (DU), and potential efficiency of the low quarter (PELQ).

\begin{tabular}{ccc}
\hline Parameter & $\begin{array}{c}\text { Flat Bed } \\
\text { Model } \\
(2)\end{array}$ & $\begin{array}{c}\text { Microtopography } \\
\text { Model } \\
(3)\end{array}$ \\
\hline TA (min) & 98.6 & 103.2 \\
TD (min) & 1090 & 595 \\
TR (min) & 1090 & 2145 \\
DU (\%) & 98.8 & 90.2 \\
PELQ (\%) & 99.3 & 89.4 \\
\hline
\end{tabular}


Table 4.Results of numerical experiment 1: standard deviation of surface elevation (SD), time of advance (TA), time of depletion (TD), time of recession at $50 \%$ of the area $\left(\mathrm{TR}_{50}\right)$, and time of recession (TR).

\begin{tabular}{ccccc}
\hline $\begin{array}{c}\mathrm{SD} \\
(\mathrm{cm}) \\
(1)\end{array}$ & $\begin{array}{c}\mathrm{TA} \\
(\mathrm{min}) \\
(2)\end{array}$ & $\begin{array}{c}\mathrm{TD} \\
(\mathrm{min}) \\
(3)\end{array}$ & $\begin{array}{c}\mathrm{TR}_{50} \\
(\mathrm{~min}) \\
(4)\end{array}$ & $\begin{array}{c}\mathrm{TR} \\
(\mathrm{min}) \\
(5)\end{array}$ \\
\hline 0.0 & 98.6 & 1090 & 1090 & 1090 \\
0.5 & 99.1 & 1010 & 1090 & 1260 \\
1.0 & 100.0 & 870 & 1090 & 1470 \\
1.5 & 100.7 & 805 & 1090 & 1645 \\
2.0 & 101.9 & 695 & 1085 & 1870 \\
2.5 & 103.2 & 595 & 1085 & 2145 \\
3.0 & 104.1 & 540 & 1085 & 2380 \\
3.5 & 105.2 & 475 & 1080 & 2635 \\
4.0 & 105.6 & 415 & 1075 & 2930 \\
4.5 & 106.2 & 425 & 1075 & 3065 \\
5.0 & 106.9 & 375 & 1075 & 3350 \\
\hline
\end{tabular}


Table 5.Results of numerical experiment 2: standard deviation of surface elevation (SD), time of cut off (TC), time of recession (TR), distribution uniformity (DU), application efficiency (Ea), gross irrigation volume $\left(\mathrm{V}_{\mathrm{g}}\right)$, volume of deep percolation $\left(\mathrm{V}_{\mathrm{dp}}\right)$, and gross irrigation depth $\left(Z_{g}\right)$.

\begin{tabular}{cccccccc}
\hline $\begin{array}{c}\mathrm{SD} \\
(\mathrm{cm}) \\
(1)\end{array}$ & $\begin{array}{c}\mathrm{TC} \\
(\mathrm{min}) \\
(2)\end{array}$ & $\begin{array}{c}\mathrm{TR} \\
(\mathrm{min}) \\
(3)\end{array}$ & $\begin{array}{c}\mathrm{DU} \\
(\%) \\
(4)\end{array}$ & $\begin{array}{c}\mathrm{Ea} \\
(\%) \\
(5)\end{array}$ & $\begin{array}{c}\mathrm{V}_{\mathrm{g}} \\
\left(\mathrm{m}^{3}\right)\end{array}$ & $\begin{array}{c}\mathrm{V}_{\mathrm{dp}} \\
\left(\mathrm{m}^{3}\right) \\
(7)\end{array}$ & $\begin{array}{c}\mathrm{Z}_{\mathrm{g}} \\
(\mathrm{m}) \\
(8)\end{array}$ \\
\hline 0.0 & 99.0 & 864 & 98.6 & 98.7 & 1039 & 14 & 0.121 \\
0.5 & 100.3 & 1010 & 97.8 & 97.5 & 1053 & 26 & 0.123 \\
1.0 & 102.4 & 1252 & 95.7 & 95.2 & 1076 & 52 & 0.125 \\
1.5 & 103.8 & 1453 & 94.4 & 93.8 & 1091 & 68 & 0.127 \\
2.0 & 106.4 & 1751 & 92.3 & 91.3 & 1119 & 97 & 0.130 \\
2.5 & 108.5 & 2089 & 90.0 & 89.2 & 1142 & 123 & 0.133 \\
3.0 & 110.6 & 2400 & 88.8 & 87.4 & 1164 & 147 & 0.136 \\
3.5 & 112.5 & 2742 & 87.2 & 85.8 & 1185 & 173 & 0.138 \\
4.0 & 114.5 & 3139 & 85.7 & 84.1 & 1207 & 192 & 0.141 \\
4.5 & 114.5 & 3279 & 85.7 & 84.1 & 1207 & 192 & 0.141 \\
5.0 & 116.2 & 3661 & 84.4 & 82.8 & 1225 & 211 & 0.143 \\
\hline
\end{tabular}




\section{APPENDIX IV: FIGURES}

Fig. 1.Experimental (symbols) and theoretical (lines) semivariograms of surface elevation for field experiments 1, 2 and 3.

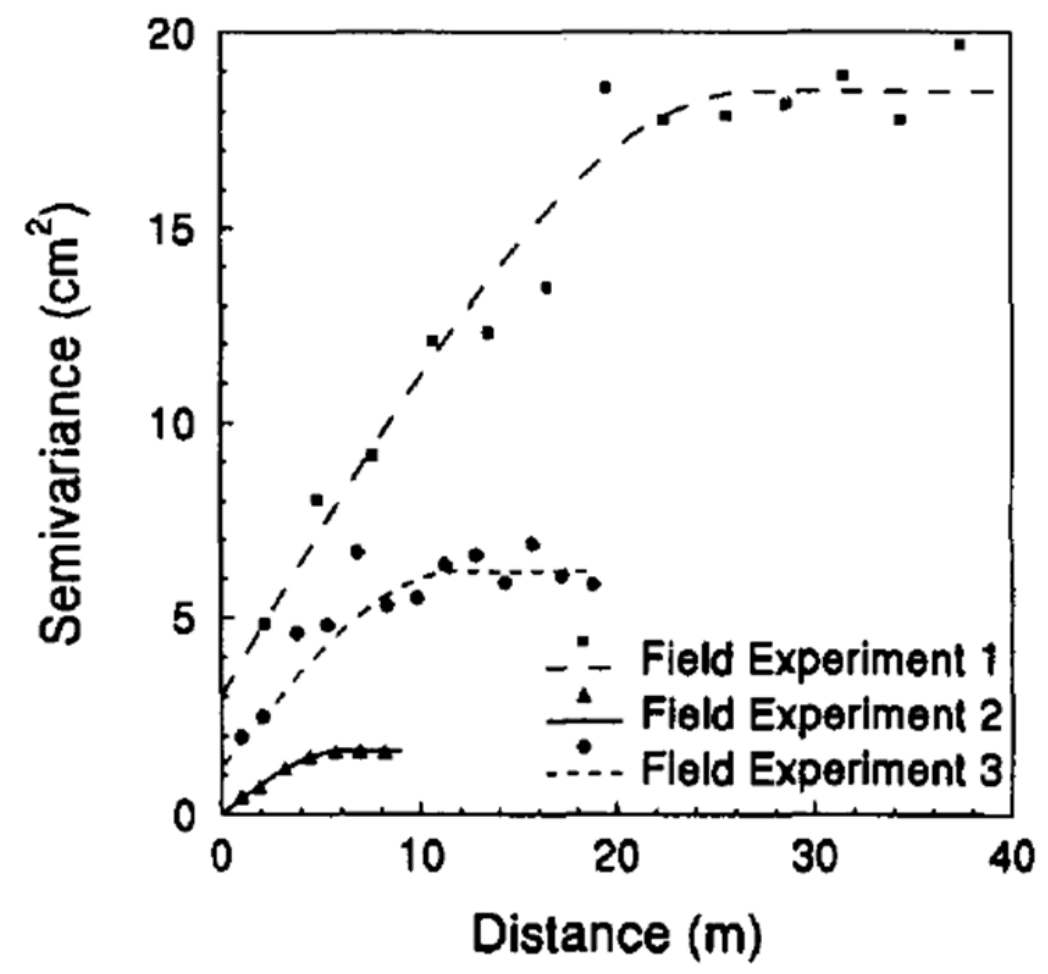


Fig. 2.Location of the advancing front in field experiment 1 at times 10 to $80 \mathrm{~min}$ as observed and simulated for cases G6D4, G3D4 and G3D0. The number following the " $G$ " indicates the grid size $(m)$; the number following the " $\mathrm{D}$ " indicates the value of the standard deviation of surface elevation (cm).

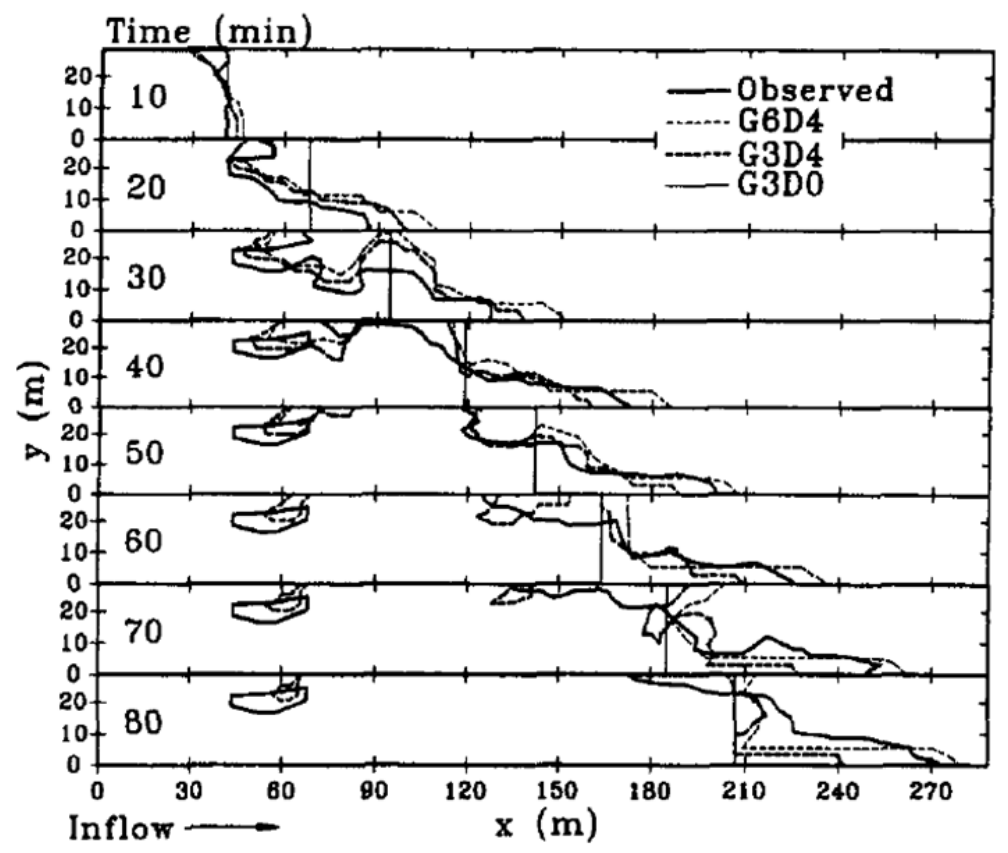


Fig. 3.Advance diagram for field experiment 1. Curves are presented for observed values and for simulation cases G6D4, G5D4, G4D4, G3D4, and G3D0. The number following the "G" indicates the grid size $(m)$; the number following the " $D$ " indicates the value of the standard deviation of surface elevation (cm).

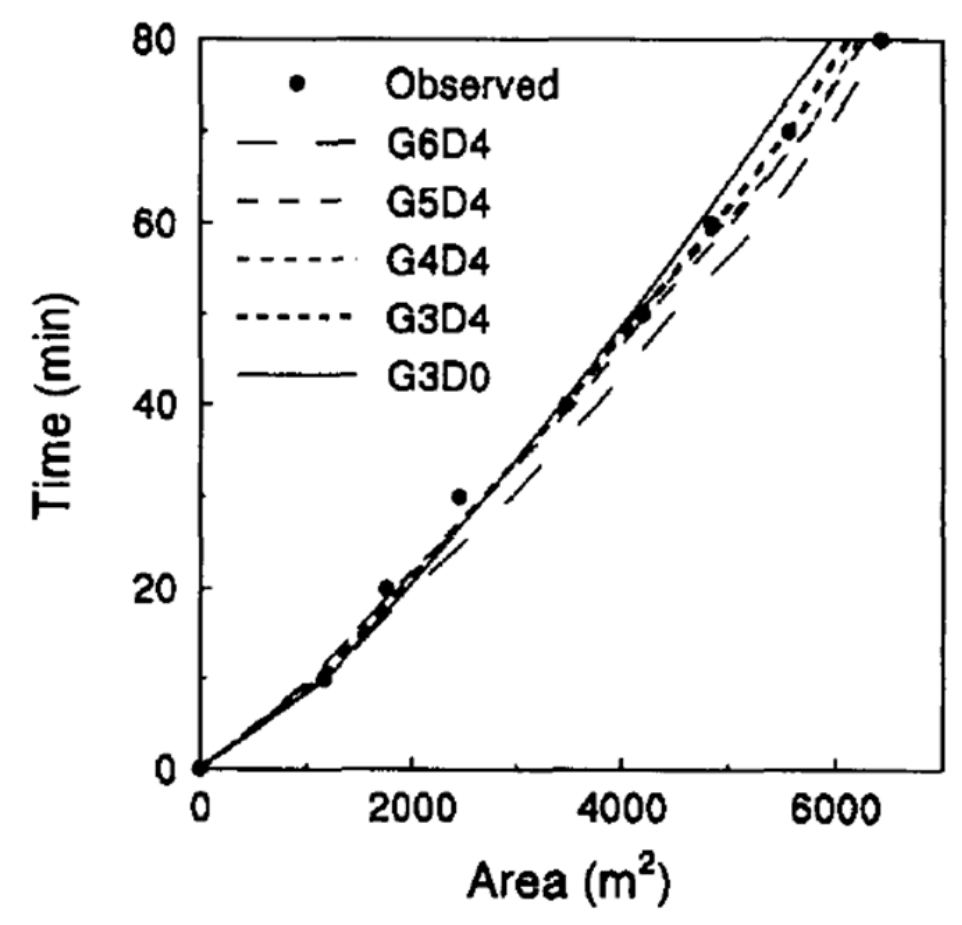


Fig. 4.Time evolution of the mass balance error for simulation cases G6D4, G5D4, G4D4, G3D4, G3D3, G3D2, G3D1 and G3D0. The number following the "G" indicates the grid size $(\mathrm{m})$; the number following the "D" indicates the value of the standard deviation of surface elevation (cm).

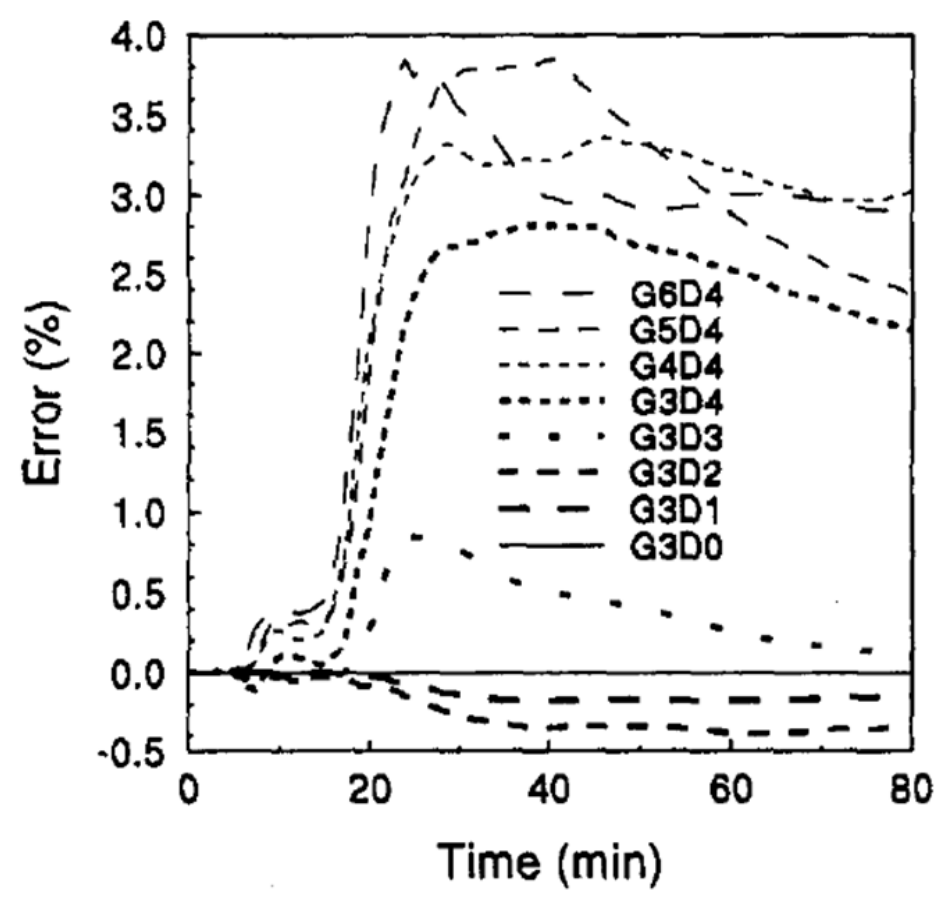


Fig. 5.Location of the recession front in field experiment 2 at different times after the time of cut off: (a) 1 hour, (b) 2 hours, (c) 3 hours and (d) 4 hours. Field observations are shaded with vertical lines; microtopography model predictions are shaded with horizontal lines.

(a)

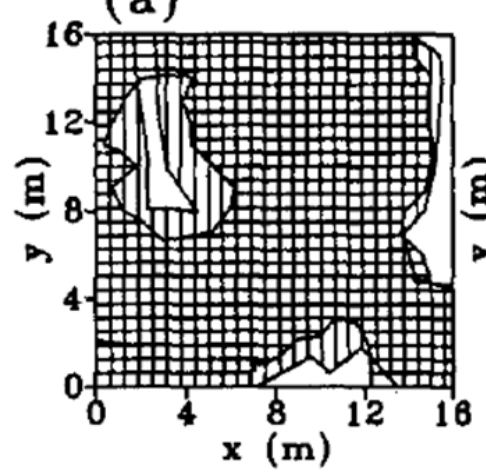

(c)

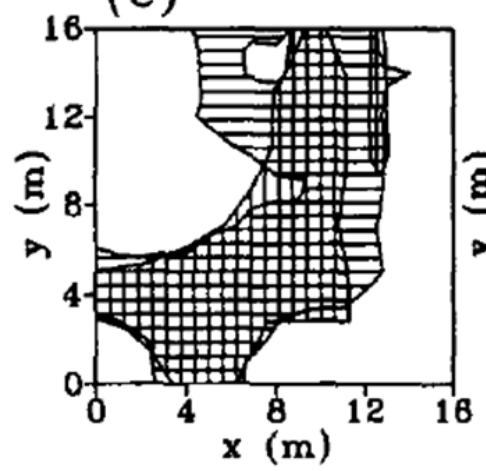

(b)

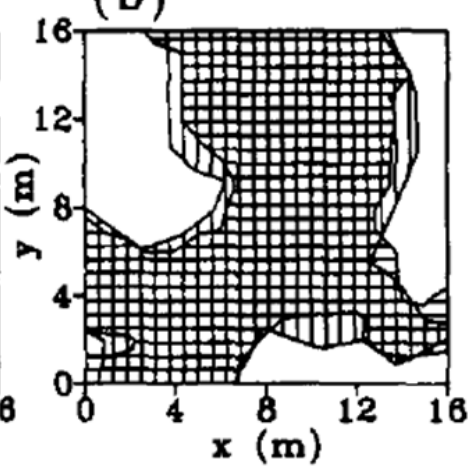

(d)

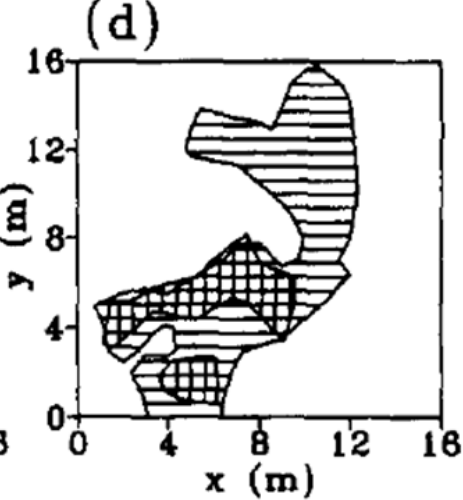


Fig. 6.Location of the advancing front in field experiment 3 at times 20, 40, 60 and 80 min as observed and simulated with a flat bed model and with the microtopography model.

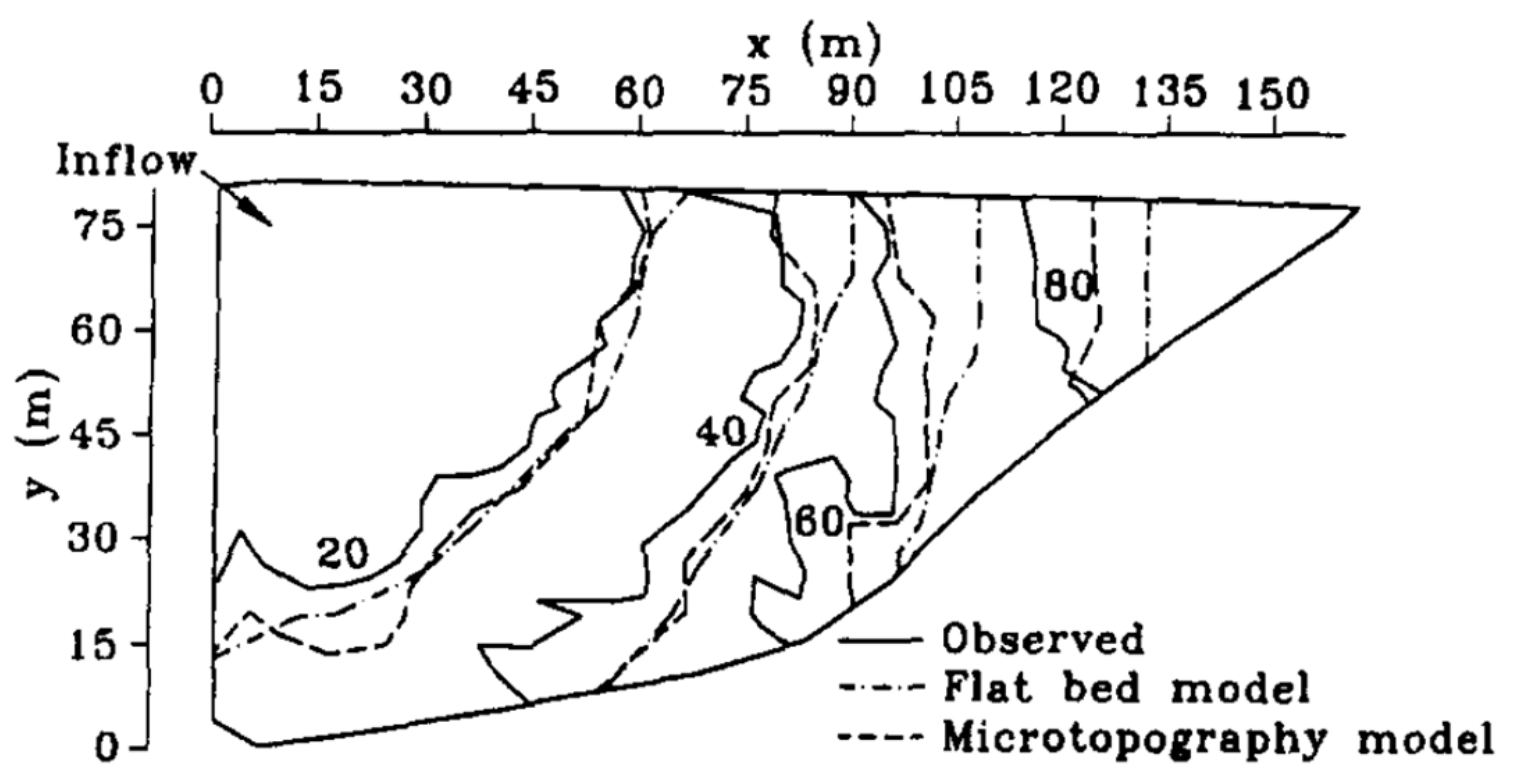


Fig. 7.Numerical experiment 1. Advance trajectory corresponding to basins with standard deviation of surface elevation (SD) of $0.0,2.5$, and $5.0 \mathrm{~cm}$.

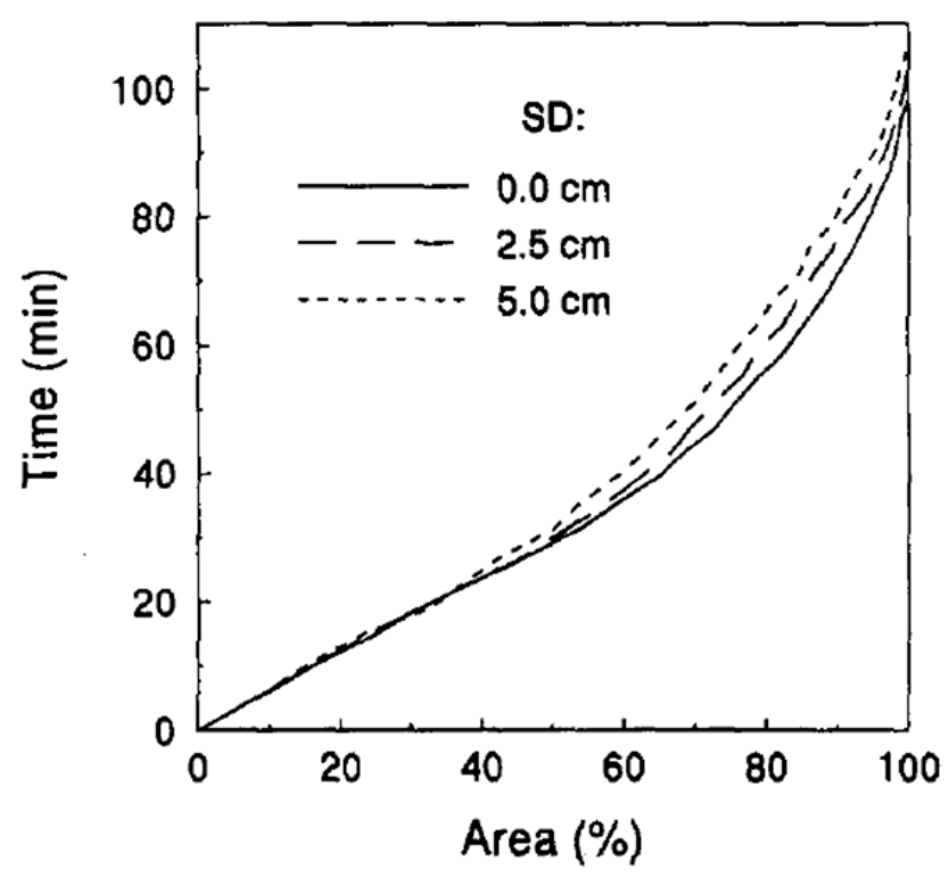


Fig. 8.Numerical experiment 1. Advance-recession diagrams corresponding to basins with standard deviation of surface elevation (SD) of 0.0, 2.5 and $5.0 \mathrm{~cm}$.

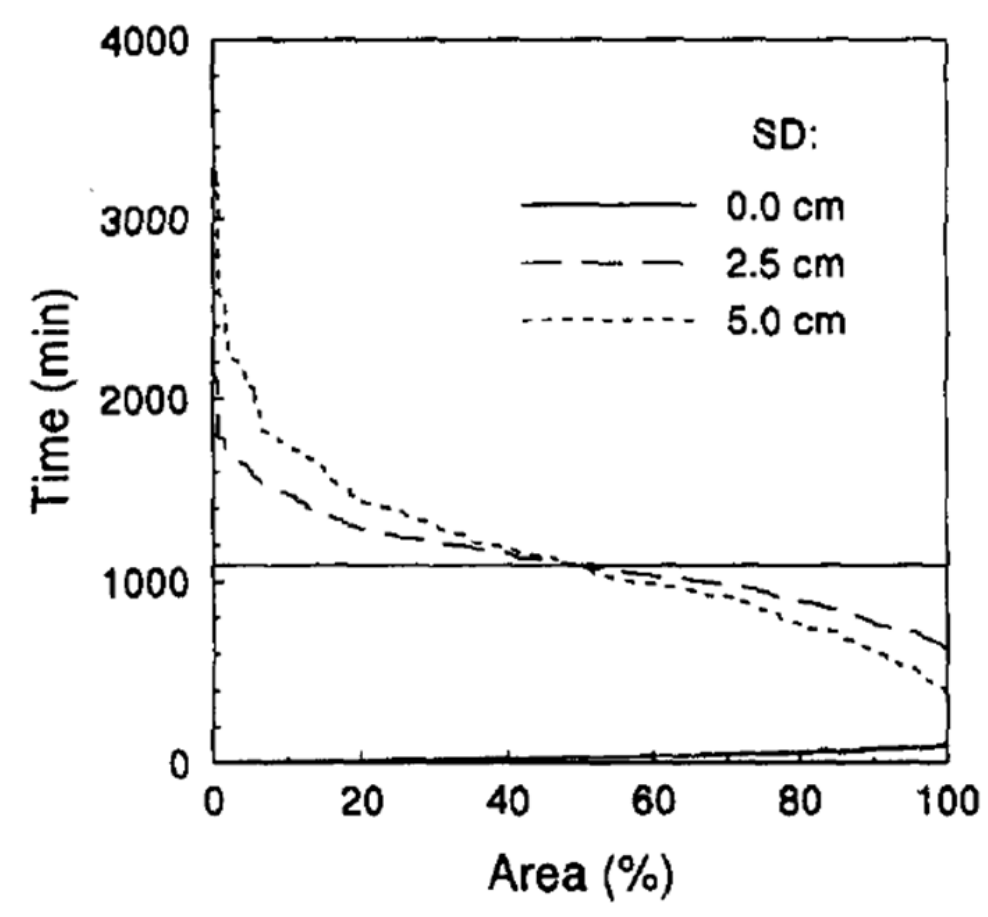


Fig. 9. Time of advance (TA), time of depletion (TD), time of recession at $50 \%$ of the area $\left(\mathrm{TR}_{50}\right)$ and time of recession (TR) vs. standard deviation of surface elevation (SD) for numerical experiment 1.

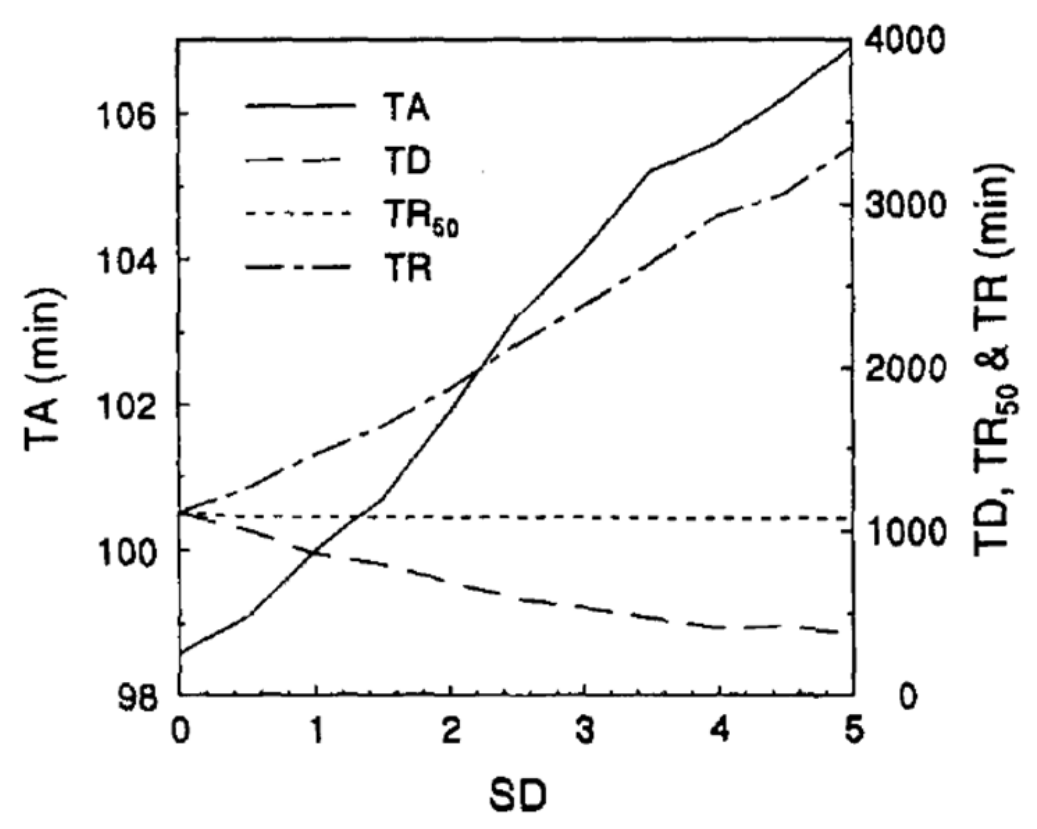


Fig. 10.Distribution uniformity (DU) and application efficiency (Ea) vs. standard deviation of surface elevation (SD) for numerical experiment 2.

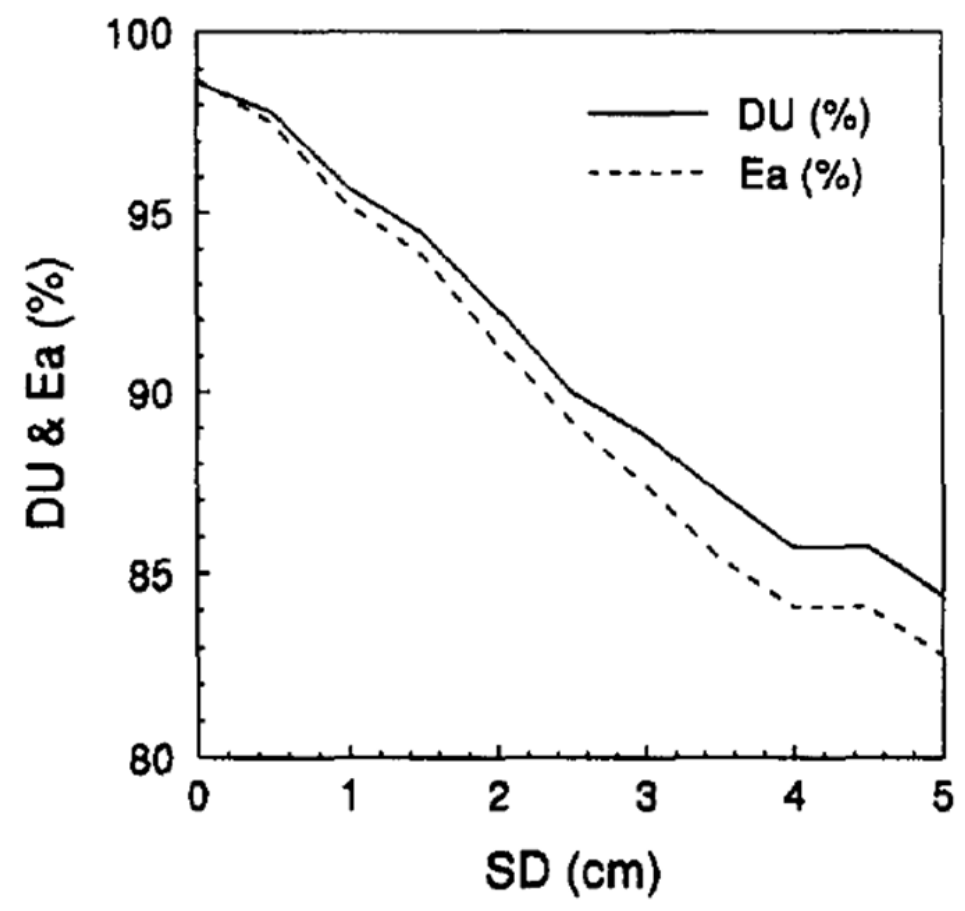


Fig. 11.Gross irrigation depth $\left(Z_{g}\right)$ and net irrigation depth $\left(Z_{n}\right)$ vs. standard deviation of surface elevation (SD) for numerical experiment 2.

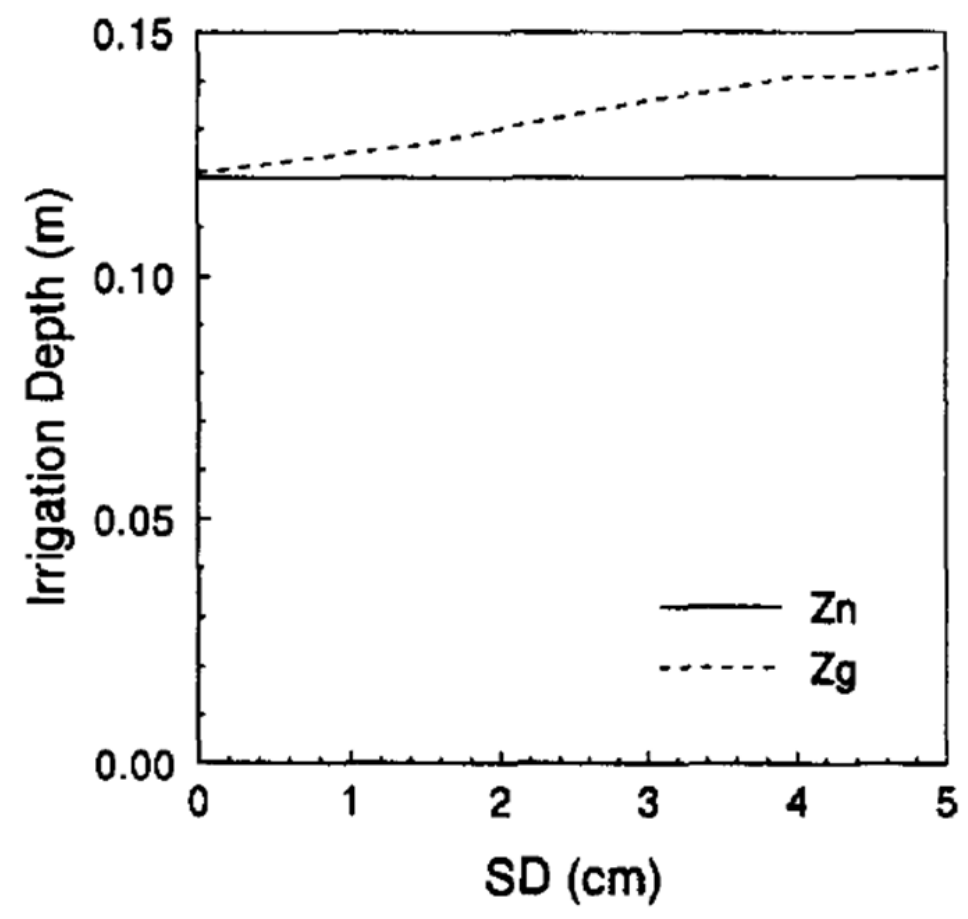

